\title{
Implementation of Multilevel Feedback Queue Algorithm in Restaurant Order Food Application Development for Android and iOS Platforms
}

\author{
Dian Andrian Ginting \\ . Student Department of \\ Computer Science \\ Faculty of Mathematics and \\ Natural Sciences \\ University of Lampung
}

\author{
Aristoteles,S.Si,M.Si \\ Lecturer Department of \\ Computer Science \\ Faculty of Mathematics and \\ Natural Sciences \\ University of Lampung
}

\author{
Ossy Dwi Endah,M.T. \\ Lecturer Department of \\ Computer Science \\ Faculty of Mathematics and \\ Natural Sciences \\ University of Lampung
}

\begin{abstract}
Rapid business development encourages every entrepreneur to create a different service to attract customers. Fast service is its own attraction for customers. Implementation of queuing or scheduling system on chefs can be used to avoid a high stack of ordering food in the chefs, so that serving times can be done quickly. Multilevel Feedback Queue scheduling algorithm is one of the CPU scheduling in the computer operating system. Multilevel feedback queue algorithms allow the process to move the queue. If a process is too time consuming, then the process will be moved to a lower queue. Therefore the interaction process becomes fewer and it reduces CPU time. On this research, we developed a food ordering web application on Android and iOS by applying multilevel feedback queue to create a queue ordering food at the chefs. The time obtained from multilevel feedback queue methods faster 30 minutes 48 seconds from the first come first serve method.
\end{abstract}

\section{Keywords}

Android, iOS, Restaurant, Queue, Web App.

\section{INTRODUCTION}

Rapid development of business encourage every entrepreneur to create a form that is different from other businesses, one of which is the restaurant business, which is exactly the fast food business, in this case requires an efficient sales system, more attractive, giving priority to the beauty, cleanliness and neatness of service, so that consumers are impressed upon entering the restaurant.

Quality of service is a dynamic state associated with products, services, people, processes, and environments that meet or have expectations with five main dimensions namely reliability, responsiveness, assurance, empathy and tangibles [1]. Quality of services, especially in the restaurant was very influential on customer satisfaction, so customers will not be disappointed or move to another restaurant.

Some of the common problems often experienced by the restaurant's Chef's food reservation buildup and the customer not convenience in ordering food, One of the solutions that can be offered is the provision restaurant tablet PC in the customer tables so that customers can easily order food. Application of queuing or scheduling system on the kitchen / chef can do to avoid the buildup of ordering food in the kitchen / chef [2].
Multilevel Feedback Queue algorithm is one that is used for scheduling the CPU in a computer operating system, multilevel feedback queue algorithms allow the process to move the queue. If a sequester process CPU too long, then the process is moved to a lower queue. This is advantageous because the process of interaction is only wearing a little CPU time. Similarly, if waiting process is too long, this process will be increased levels.

In this research, developed a food ordering web app on Android and iOS platform by applying multilevel feedback queue to create a queue ordering food at the chef, so that the time spent on food preparation faster than the First Come First Serve methods and improve the efficiency of time in the restaurant.

\section{METHODS}

For the model queue that was used in this study is a Multi Channel, Single Phase queue model (M/M/S) and for the development of system application using the prototyping method with the programming language PHP and MySQL.

\subsection{JQuery Mobile}

JQuery Mobile is a touch -optimized web framework (a library of JavaScript or mobile framework). JQuery Mobile is focused on creating a framework that is compatible with a wide range of smartphones and tablet computer, was created for the creation of applications that can run on a smartphone or tablet such as web apps. (JQuery Documentation, 2013) Some of the advantages JQuery Mobile, among others:

1. Compatible with all major mobile platforms as well as all major desktop browsers, including iOS, Android, Blackberry, WebOS, Symbian, Windows Phone, and more.

2. Built on top of jQuery core so it has a minimal learning curve for people already familiar with jQuery syntax.

3. Theming framework that allows creation of custom themes.

4. Limited dependencies and lightweight to optimize speed.

5. The same underlying codebase will automatically scale to any screen.

6. HTML5-driven configuration for laying out pages with minimal scripting.

7. Ajax-powered navigation with animated page transitions that provides ability to clean URLs through pushState. 
8. UI widgets those are touch-optimized and platformagnostic.

\subsection{Multi Channel, Single Phase (M/M/S)}

Multi-Channel Single Phase occurs whenever two or more service facilities fed by a single queue.

Examples of queuing systems can be seen in Figure 1. Meaning of (M / M / S) is the Multi-Channel Model is composed of:

1. The first $\mathrm{M}$ is the average arrivals follow a Poisson probability distribution.

2. The second $\mathrm{M}$ is the level of service that follows an exponential probability distribution

3. $\mathrm{S}$ is the number of system or service facilities in more than one channel.

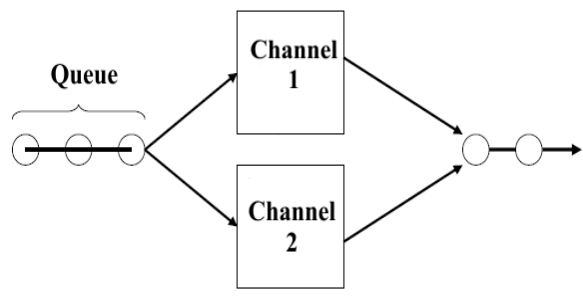

Figure 1 Multi Channel, Single Server Queue Model

M / M / s (Multiple Channel Model) works according Heizer [3] is using the following formula:

$$
\begin{aligned}
& P_{0}=\frac{1}{\left[\sum_{n=0}^{M-1} \frac{1}{n !}\left(\frac{\lambda}{\mu}\right)^{n}\right]+\frac{1}{M !}\left(\frac{\lambda}{\mu}\right)^{M} \frac{M \mu}{M \mu-\lambda}} \\
& L_{s}=\frac{\lambda \mu\left(\frac{\mu}{\lambda}\right)^{M}}{(M-1) !(M \mu-\lambda)^{2}} P_{0}+\frac{\lambda}{\mu} \\
& W_{s}=\frac{L_{s}}{\lambda} \\
& L_{q}=L_{s}-\frac{\lambda}{\mu} \\
& W_{q}=\frac{L_{q}}{\lambda} \\
& P_{n}=\frac{\left[\frac{\lambda}{\mu}\right]^{1}}{n !} P_{0}
\end{aligned}
$$

\subsection{Multilevel Feedback Queue}

Multilevel feedback queue is one algorithm based on the model of Multi-Channel Single server queue. Fundamental advantages possessed by the multilevel feedback queue are the possibility of a process of moving from one queue to another queue, for instance with lower priority or higher [4].

On Multilevel feedback queue there are some important rules:

- If the Priority (A)> Priority (B), then A is executed (not B).

- If the Priority (A) = Priority (B), A \& B algorithm running on FSFC (First Come, First Serve).

- If a job is entered into the system, then the work comes into the category highest priority (the topmost queue).
- If the job requires extra time when running, its priority lowered (e.g., displacement of the queue).

- If the work is completed before time, permanent jobs at the same level.

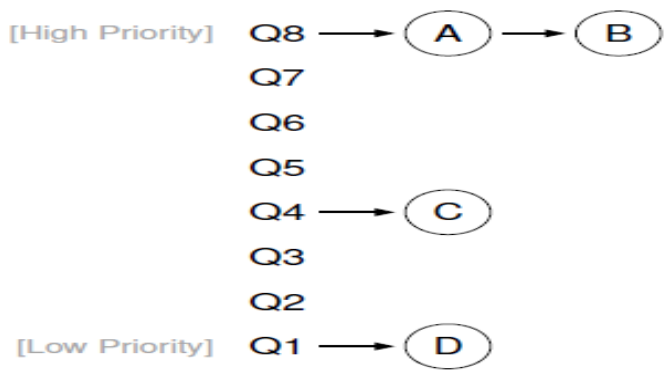

Figure 2 Multilevel Feedback Queue Examples

In Figure 2 there is a job (Job A and B) have the highest priority level, and job $\mathrm{C}$ and $\mathrm{D}$ are at a low priority level. Then the work will be done by the CPU is job A $\rightarrow \mathrm{B} \rightarrow \mathrm{C} \rightarrow$ D.

\subsection{Protyping Methods}

With this prototyping method developers and customers can interact with each other during the making of the system. To overcome the inconsistency between the customer and the developer, it must needs good cooperation between the two so that developers will know exactly what the customer wants not rule out technical aspects and customers will know the finishing processes in the desired system, thus will produce a system in accordance with specified completion the time schedule [5]. Summary prototypes in this research are shown in Table 1 .

Table 1 Prototype Module

\begin{tabular}{|c|l|}
\hline Prototype & \multicolumn{1}{|c|}{ Generated functions } \\
\hline 1 & $\begin{array}{l}\text { 1. Function in jQuery to run the } \\
\text { program on the iOS and Android } \\
\text { platform }\end{array}$ \\
2. Function for detecting screen \\
resolution and orientation on PC \\
tablet
\end{tabular}

\subsection{Queue}

Hiller [6] split system queues into three components:

\section{Calling Population}


According to its size, population to be served can finite or may infinite. Arrival pattern can be regular, it could be random.

2. Queue

Queue length could be limited or may not be limited.

3. Service Facilities

Characteristics of service facilities can be seen from the three cases, the layout physically from the system queue, queue discipline, service time.

Such models conventionally are labeled as follows:

Distribution of interarrival times
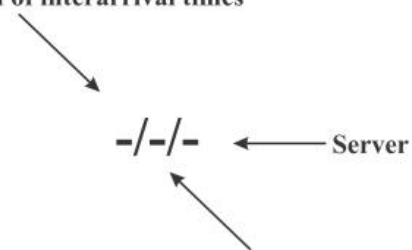

Distribution of interarrival times

\subsection{Web Applications (Webapps)}

Web Applications (Web Apps) is an application that is accessed by users via a network such as the internet or intranet Apers[7]. Web Apps can also be interpreted as software encoded with programming that can be integrated with the browser, usually used programming is combined with HTML JavaScript. A Web Apps basically have 3 layers. In the first layer is on the client side that has the basic browser system. In the second layer contained dynamic content generation tools such as JavaScript and php. In the third layer contained and consists of a data storage back end of the database such as MySQL or Oracle.

\section{DISCUSSION}

\subsection{Description of Applications}

The initial application named "Mejuah - Juah Resto". Application name can be changed based restaurant wants to use the application. Function of this application is the food at the restaurant ordering application on the tablet platform: Android tablets and ipad. This application uses an algorithm Multilevel Feedback Queue (MLFQ) to resolve the problems buildup on the chef. This application was developed with a mobile website application structure. In addition, this application is included on the website for the admin panel to process data of food. To view screenshots of the application shown in Figure 3.

This application consists of a few main menu:

\section{Home Menu}

Home function is to provide information to customers latest news in the form of menus and often ordered menu.

2. Ordering Food Menu

This menu function is ordering food menu that consists of the name of the food, the price of food as well as presentation time. Ordering menu is divided

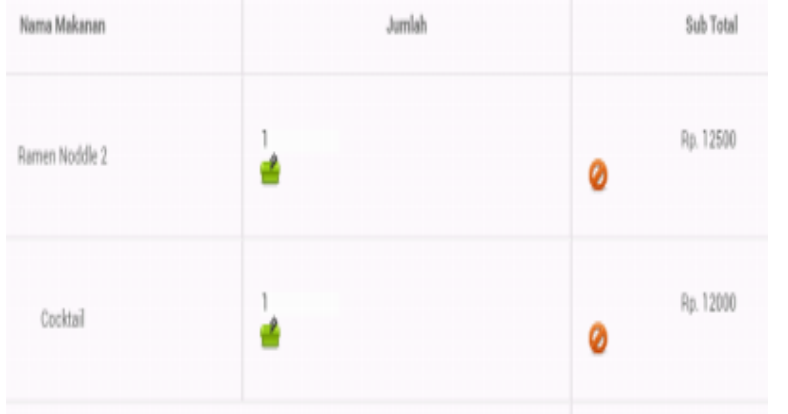

by food categories, namely: Opening, Main, Extras and Desert.

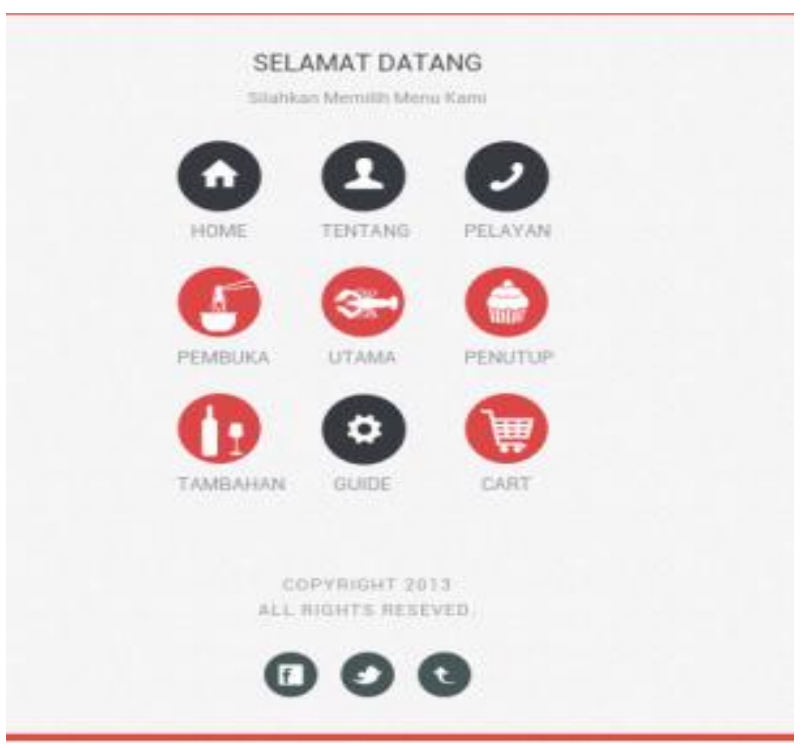

3. Order Cart

This orders cart function to accommodate customer orders list that will be sent to the chef.

Figure 3 Mejuah-juah Resto Screenshot

\subsection{Application Development Assumption}

Assumption is that the range of conditions specified study / research undefined. The assumptions used in this research are:

1. iPad / tablet used in restaurants can run for working period.

2. Every table in the restaurant had an iPad/tablet. In this study it is assumed the number of the table is 20 and has active status if there are customers as well as inactive if there are no customers.

3. Reservations food queue is using by chefs, so they can serve food quickly so that customers do not wait too long.

4. In the kitchen has a screen to display a list of queues and the number of food ordering food table, where the food was ready the waiters deliver food to the customer table.

5. Application does not set staffing issues and profits earned by the restaurant.

6. Chef considered the server of a queue system that provides reservation service.

7. Number of chefs in assuming there are 4 people and each chef can serve each category of food is opening food, main, dessert and extras.

8. Each - each chef can serve all types of food and all food categories.

9. Server can serve 4 meals ordering process at once.

10. All orders are entered into the server simultaneously.

11. Each chef can only serve a maximum of 10 food items / food.

12. Food presentation with time 00:00:00 will not go into a queue system, but will direct presented by the waitress.

13. The food will be presented in the application has a maximum time is 00:20:00. 


\subsection{Multilevel Feedback Queue Algorithm Implementation}

MLFQ can change the priority level of the existing queuing system, the changes made to benefit from the services and simultaneously reduce / eliminate the queue (waiting time). For models of Multilevel Feedback Queue can be seen in the flowchart in Figure 4.

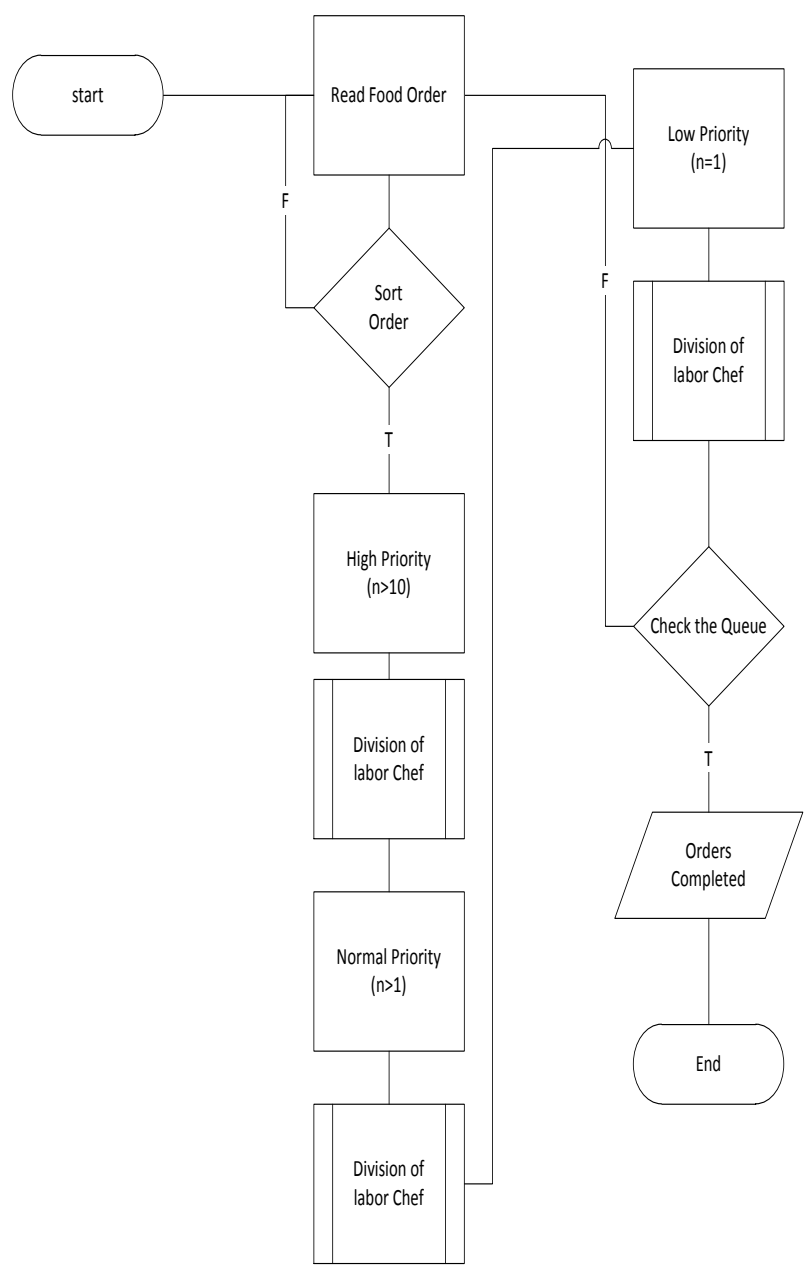

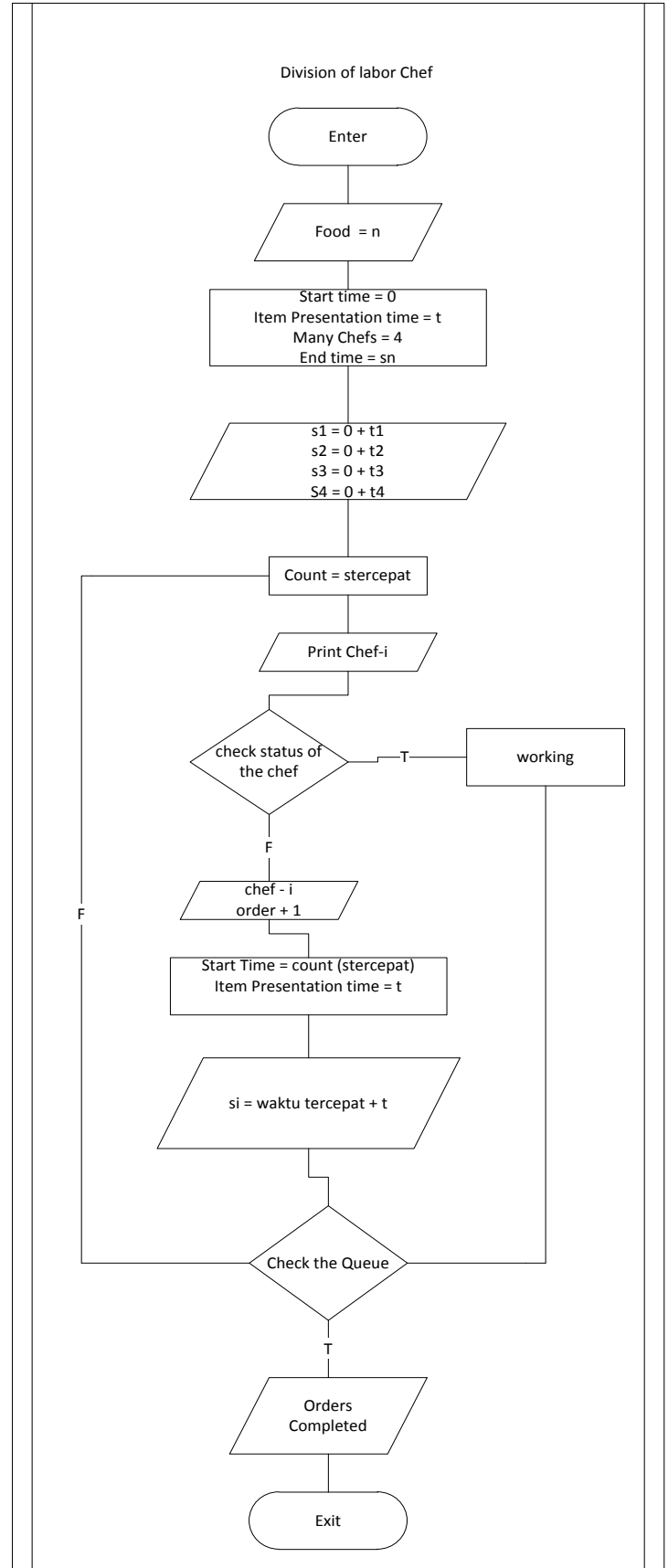

Figure 4 Multilevel Feedback Queue Flowcharts

\subsection{Analysis of Multi Channel, Single Phase (M/M/S) Queue}

If restaurants using chef by 4 people, and available 20 of the table and assumed to rush hour there are 20 order / hour entering the server.

Based on the assumption that has been created, can then be calculated: 
Table 2 Analysis M/M/S Queue

\begin{tabular}{|c|c|c|}
\hline Notation & Unit & Value \\
\hline $\mathrm{T}$ & 1 & Hour \\
\hline$\lambda$ & 20 & Table/Hour \\
\hline$\mu$ & 20 & Table/Hour \\
\hline $\mathrm{M}$ & 4 & Unit \\
\hline$\rho$ & 0.25 & \\
\hline Po & 0.367346939 & \\
\hline $\mathrm{L}$ & 1,0068 & User \\
\hline $\mathrm{Lq}$ & 0,0068 & User \\
\hline $\mathrm{W}$ & 0,05034 & Hour \\
\hline $\mathrm{Wq}$ & 0.00034 & Hour \\
\hline \multicolumn{3}{|c|}{ The probability of the capacity in the system } \\
\hline $\mathrm{n}$ & \multicolumn{2}{|c|}{$P_{n}$} \\
\hline 0 & \multicolumn{2}{|c|}{0.367346939} \\
\hline 1 & \multicolumn{2}{|c|}{0.367346939} \\
\hline 2 & \multicolumn{2}{|c|}{0.183673469} \\
\hline 3 & \multicolumn{2}{|c|}{0.06122449} \\
\hline 4 & \multicolumn{2}{|c|}{0.015306122} \\
\hline 5 & \multicolumn{2}{|c|}{0.003826531} \\
\hline 6 & \multicolumn{2}{|c|}{0.000956633} \\
\hline 7 & \multicolumn{2}{|c|}{0.000239158} \\
\hline
\end{tabular}

\subsection{Comparison of Food Serving Time and Channel Distribution FCFS with MLFQ}

Comparison of presentation time was calculated to determine the optimal food serving time from manually methods First Come First Serve (FCFS) method and Multilevel Feedback Queue (MLFQ). FCFS method is used for comparison because this method is similar to the conventional method, orders are entered into the system will be done, so the next order must wait the first order completed.

For the division of work (channel) of chef has several processes, namely:

1. 4 queues of incoming orders in the first will be done by each chef.

2. If the chef is still working on the food order status is working.
3. To next food order queue it will be done by a chef who has finished working on the previous order (Status Available).

\subsubsection{Execution of Order Food with FCFS Method}

Way of working the FCFS method used in this study is any order that comes into the server (kitchen) will be directly done by chefs. For food preparation time with the FCFS method using four chefs can be seen in Table 3. For total work time is calculated based on the total time of each chef cooks and chefs who take the longest time.

Table 3 Making Food Time With FCFS With Four Chefs

\begin{tabular}{|c|c|c|}
\hline Order No & $\begin{array}{c}\text { Total Time } \\
\text { Orders }\end{array}$ & Working Chef \\
\hline 1 & 01:08:10 & 1 \\
\hline 2 & $00: 15: 41$ & 2 \\
\hline 3 & $00: 32: 30$ & 3 \\
\hline 4 & $00: 22: 00$ & 4 \\
\hline 5 & $00: 25: 30$ & 2 \\
\hline 6 & 00:20:00 & 4 \\
\hline 7 & $00: 12: 00$ & 3 \\
\hline 8 & $00: 20: 11$ & 2 \\
\hline 9 & 00:06:00 & 4 \\
\hline 10 & $00: 14: 30$ & 3 \\
\hline 11 & $00: 41: 48$ & 4 \\
\hline 12 & $00: 42: 33$ & 3 \\
\hline 13 & 00:00:00 & 2 \\
\hline 14 & 00:00:00 & 2 \\
\hline 15 & 00:05:00 & 2 \\
\hline 16 & $00: 05: 30$ & 2 \\
\hline 17 & $00: 53: 00$ & 1 \\
\hline 18 & $00: 05: 30$ & 2 \\
\hline 19 & $00: 15: 00$ & 2 \\
\hline 20 & 00:32:00 & 4 \\
\hline \multicolumn{2}{|c|}{ Total Time } & 02:01:48 \\
\hline
\end{tabular}




\subsubsection{Execution of Order Food with MLFQ Method}

For the MLFQ methods following process:

1. Each order is entered into the server will be collected and categorized based on the same menu id.

2. Items with the highest number goes into high priority, and the data will be sorted by the amount of food the food.

3. Items with the same amount will be sorted by the time of presentation.

4. Item with the smallest amount goes into a low priority.

For food preparation time with the MLFQ method using four chefs can be seen in Table 4. For total work time is calculated based on the total time of each chef cooks and chefs who take the longest time.

Table 4 Making Food Time With MLFQ With Four Chefs

\begin{tabular}{|c|c|c|c|c|}
\hline $\begin{array}{l}\text { Menu } \\
\text { ID }\end{array}$ & Total & Item & $\begin{array}{c}\text { Time } \\
\text { Orders }\end{array}$ & Chef \\
\hline \multirow{5}{*}{36} & \multirow{5}{*}{45} & 10 & 00:15:00 & 1 \\
\hline & & 10 & $00: 15: 00$ & 2 \\
\hline & & 10 & 00:15:00 & 3 \\
\hline & & 10 & 00:15:00 & 4 \\
\hline & & 5 & 00:15:00 & 1 \\
\hline \multirow{3}{*}{18} & \multirow{3}{*}{29} & 10 & 00:01:00 & 2 \\
\hline & & 10 & 00:01:00 & 3 \\
\hline & & 9 & 00:01:00 & 4 \\
\hline \multirow{3}{*}{35} & \multirow{3}{*}{29} & 10 & 00:10:11 & 2 \\
\hline & & 10 & 00:10:11 & 3 \\
\hline & & 9 & 00:10:11 & 4 \\
\hline \multirow{3}{*}{31} & \multirow{3}{*}{29} & 10 & 00:12:00 & 2 \\
\hline & & 10 & 00:12:00 & 3 \\
\hline & & 11 & $00: 12: 00$ & 4 \\
\hline \multirow{3}{*}{40} & \multirow{3}{*}{27} & 10 & 00:20:00 & 1 \\
\hline & & 10 & 00:20:00 & 2 \\
\hline & & 7 & 00:20:00 & 3 \\
\hline \multirow{2}{*}{2} & \multirow{2}{*}{19} & 10 & 00:08:59 & 4 \\
\hline & & 9 & 00:08:59 & 4 \\
\hline \multirow{2}{*}{23} & \multirow{2}{*}{17} & 10 & 00:10:00 & 1 \\
\hline & & 7 & 00:10:00 & 2 \\
\hline \multirow{2}{*}{32} & \multirow{2}{*}{17} & 10 & 00:05:00 & 3 \\
\hline & & 7 & 00:05:00 & 4 \\
\hline \multirow{2}{*}{6} & \multirow{2}{*}{12} & 10 & 00:05:30 & 1 \\
\hline & & 2 & 00:05:30 & 3 \\
\hline 7 & 8 & 8 & 00:05:00 & 4 \\
\hline 4 & 8 & 8 & 00:09:00 & 1 \\
\hline 28 & 7 & 7 & 00:05:30 & 2 \\
\hline 19 & 3 & 3 & 00:07:00 & 3 \\
\hline 24 & 2 & 2 & 00:05:00 & 4 \\
\hline
\end{tabular}

\begin{tabular}{|c|c|c|c|c|}
\hline 5 & 2 & 2 & $00: 05: 30$ & 4 \\
\hline 29 & 2 & 2 & $00: 07: 30$ & 1 \\
\hline 16 & 1 & 1 & $00: 02: 00$ & 2 \\
\hline 8 & 1 & 1 & $00: 03: 00$ & 3 \\
\hline 14 & 1 & 1 & $00: 05: 30$ & 2 \\
\hline 10 & 1 & 1 & $00: 13: 10$ & 3 \\
\hline \multicolumn{5}{|c|}{ Total Time } \\
\hline
\end{tabular}

MLFQ method using 01 hours 41 minutes 40 seconds, with this method of food preparation faster about 30 minutes 08 seconds compared to the FCFS method. For the view MLFQ working by system can be seen in Figure 10 .

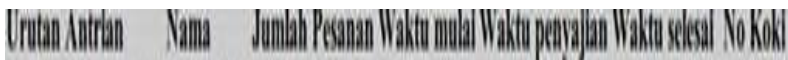

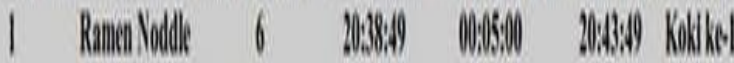

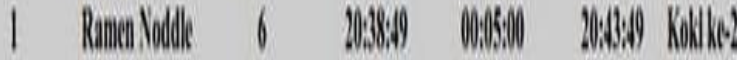

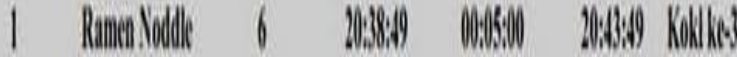

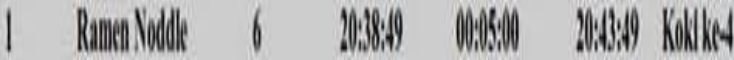

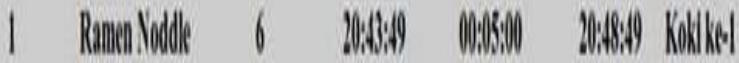

Figure 5 MLFQ Working Progress

\section{CONCLUSION}

For the the model and analysis of queuing systems used is M / $\mathrm{M} / \mathrm{S}$, this analysis is used to calculate the optimal time in the making when the queue server. M / M / S queue model will be implemented in the MLFQ the priority order of making food that is high priority and low priority to minimize the time of the presentation of the food.

In the manufacture of queuing systems on the chef, there are worst case when use MLFQ, if the order only contains 3 items, the FCFS method is more optimal from MLFQ because working requires only 3 cooks and does not require a lot of working processes.

This application also has some other shortcomings such as transaction id is created based on a unique time and table number still manually inputting, for further research can be expected to make the transaction id based on IP Address. Hardware support especially tablets and wireless networks are indispensable for the application of the system in real applications restaurant.

\section{LIST OF SYMBOLS}

$\mu=$ Average service rate

$\lambda=$ Average arrival rate

$\mathrm{Po}=$ Probability of no individual in the system

$\mathrm{Pn}=$ Probability of the capacity in the system

$\mathrm{Ls}=$ The average number of customers in the system

$\mathrm{Lq}=$ Average number of customers in the queue

Ws $=$ The average time it takes a customer in the system

$\mathrm{Wq}=$ Average time it takes a customer in the queue

$\mathrm{Ws}=$ The average time it takes a Customer in the system

$\mathrm{Wq}=$ Average time it takes a customer in the queue 


\section{REFERENCES}

[1] Tjiptono, Fandy. 2005. Pemasaran Jasa. Malang : Bayumedia Publishing.

[2] Simenonov,Simeon \& Jana Simeonovova.Simulation Scheduling in Food Industry Application.Czech J. Food Sci,Vol. 20, No. 1: 31-37,2007.

[3] Heizer, Jay \& Barry Render.2010.Operations Management:Tenth Edition.New Jersey:Prentice Hall PTR.
[4] Dusseau-Arpaci.2012.Operating Systems: Three Easy Pieces.Madison:The University of Wisconsin.

[5] McLeod Jr,Raymond \& George P. Schell.2008.Sistem Informasi Manajemen edisi 10.Jakarta:Salemba Empat.

[6] Hiller, Frederick S \& Gerald J. Lieberman.1967.Intoduction To Operation Research:Fifth Edition.New York:MCGraw-Hill.

[7] Apers,chris \& Daniel Paterson. 2012. Beginning iPhone and iPad Web Apps Scripting with HTML5,CSS3 \& Javascript.New York:Apress. 